\title{
ERCP using a conventional upper gastrointestinal endoscope for a patient with a type I duodenal stricture
}

Combined obstruction of the bile duct and duodenum is a common occurrence in periampullary malignancies [1,2]. If a duodenoscope cannot be used in the case of type I duodenal strictures, endoscopic ultrasonography drainage or percutaneous transhepatic biliary drainage are used for treating obstructive jaundice or acute cholangitis [3]. However, depending on the hospital, these options may not be possible. Although the use of an ultraslim endoscope has been described [4], the working channel is limited. Here we report a case of successful endoscopic biliary drainage using a conventional upper gastrointestinal (GI) endoscope.

A 71-year-old woman with a type I duodenal stricture due to gallbladder cancer underwent endoscopic retrograde cholangiopancreatography (ERCP) for obstructive jaundice. Contrast-enhanced computed tomography had revealed gallbladder cancer and intrahepatic duct dilatation ( $>$ Fig. 1). We attempted endoscopic biliary drainage (EBD) using a duodenoscope (TJF-260V; Olympus, Tokyo, Japan); however, the scope could not pass the duodenal stricture ( $\boldsymbol{F}$ Fig. $\mathbf{2}$ a, b). Therefore, we attempted ERCP using a conventional upper $\mathrm{Gl}$ endoscope (GIFQ260; Olympus) (\Video 1). First, we passed through the duodenal stricture using the upper Gl endoscope. This endoscope was retroflexed in the descending portion of the duodenum ( $\triangleright$ Fig.3a), allowing observation of the major papilla ( $\vee$ Fig.3b). Then, the cannulation device was inserted into the bile duct ( $\nabla$ Fig. $3 \mathbf{c}$ ), and the guidewire (GW) was advanced into the left hepatic duct. Finally, the EBD tube (7-Fr plastic stent, Flexima; Boston Scientific, Tokyo, Japan) was inserted into the left hepatic duct over the guidewire. There were no adverse events during the endoscopic procedure.

In this approach, the endoscope was stabilized by retroflexion. Cannulation into the bile duct was simple, because

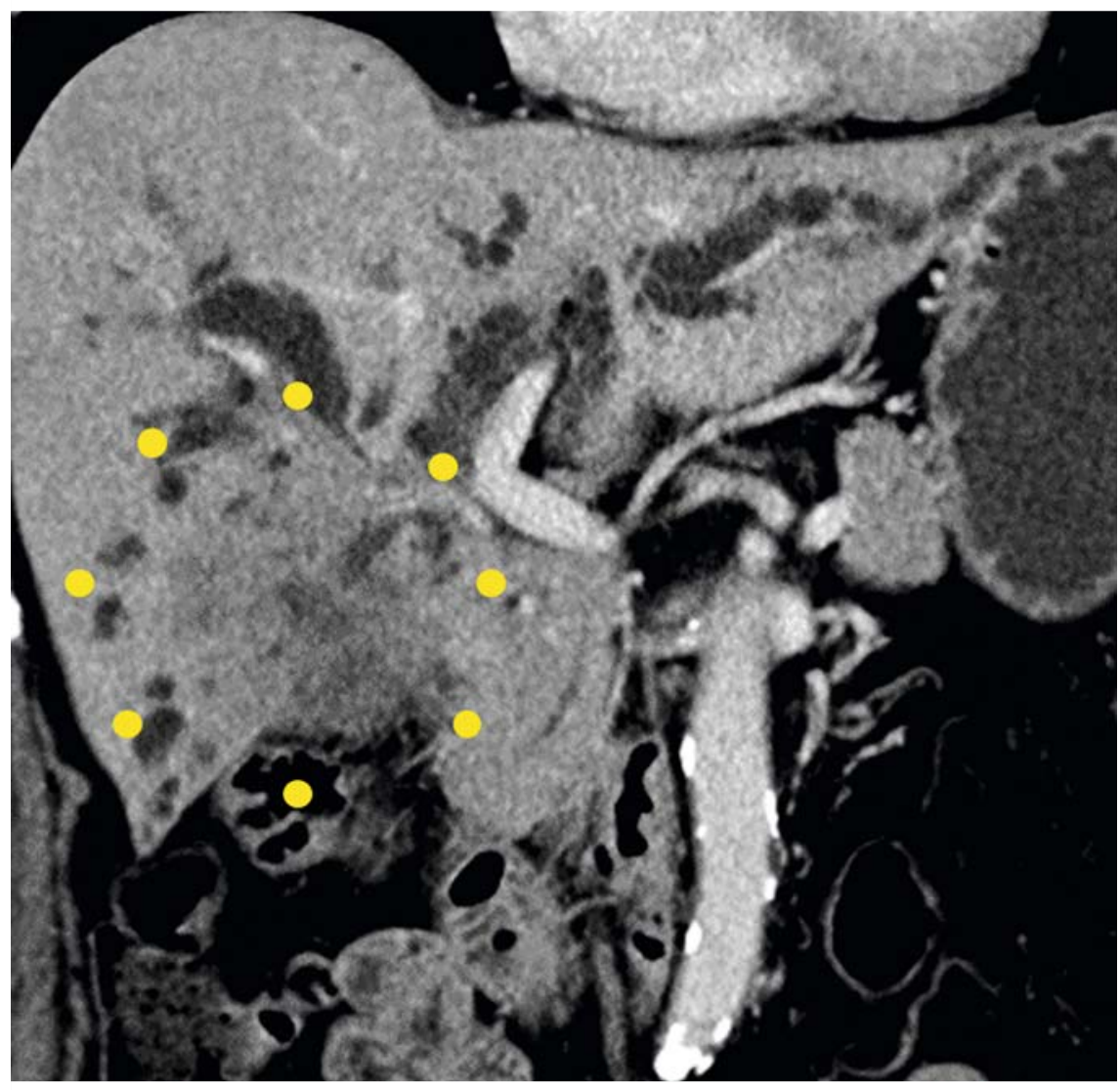

- Fig. 1 Gallbladder cancer (area inside yellow dots) and intrahepatic duct dilatation, shown by contrast-enhanced computed tomography.
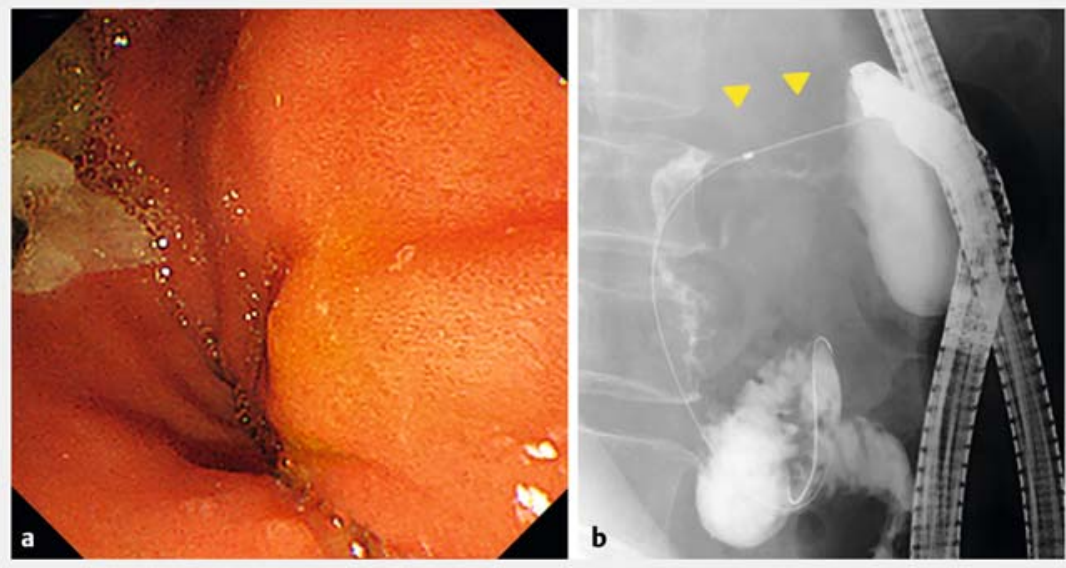

Fig. 2 a Endoscopic view of duodenal stricture. b The duodenoscope could not pass the duodenal stricture (yellow arrows). 

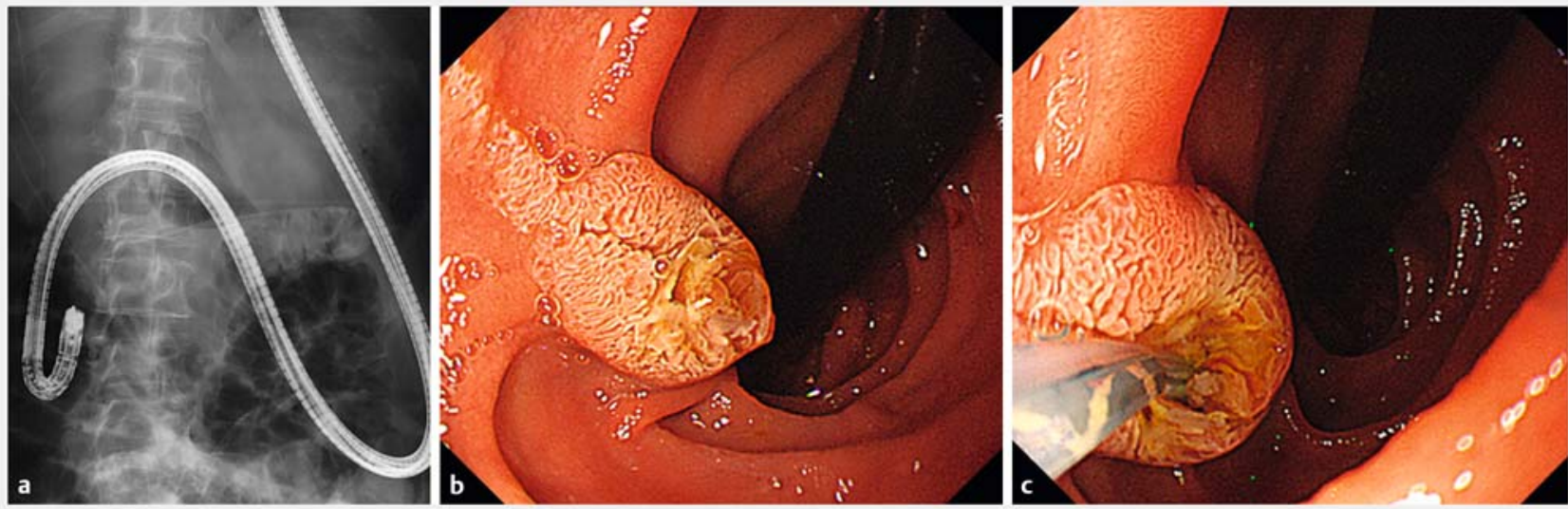

- Fig. 3 a The upper gastrointestinal endoscope was retroflexed in the descending portion of the duodenum. $\mathbf{b}$ Retroflexion view of the major papilla. c Cannulation of the bile duct.

the bile duct and the cannulation device were aligned in a straight line. As a conventional upper gastrointestinal endoscope is highly versatile, this method may be used by any endoscopist.

Endoscopy_UCTN_Code_TTT_1AR_2AK

Competing interests

None

The authors

Hirotsugu Maruyama, Yuki Kakiya-Ishikawa, Kojiro Tanoue, Kappei Hayashi, Masafumi Yamamura, Yasuaki Nagami, Yasuhiro Fujiwara

Department of Gastroenterology, Osaka City University Graduate School of Medicine, Osaka, Japan

\section{Corresponding author}

\section{Hirotsugu Maruyama, MD}

Department of Gastroenterology, Osaka City University Graduate School of Medicine,

1-4-3, Asahimachi, Abeno-ku, Osaka,

545-8585, Japan

Fax: +81-6-66453813

hiromaruyama99@gmail.com

\section{References}

[1] Khullar SK, DiSario JA. Gastric outlet obstruction. Gastrointest Endosc Clin N Am 1996; 6: 585-603

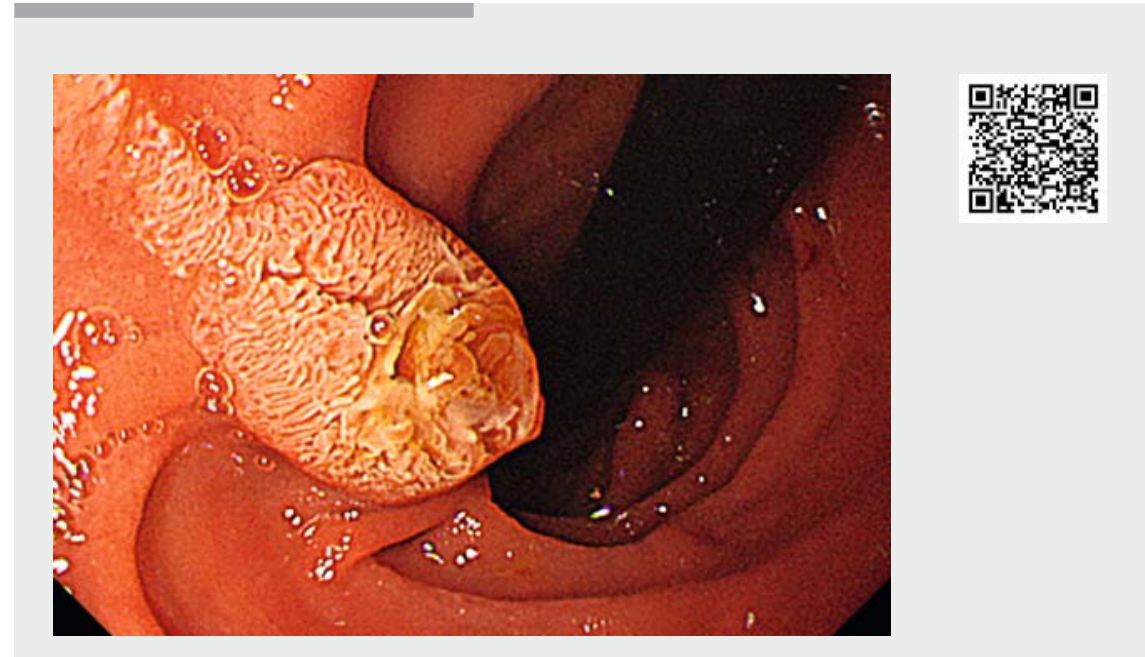

Video 1 Endoscopic biliary drainage using a conventional upper gastrointestinal endoscope.

[2] Johnson CD, Ellis H. Gastric outlet obstruction now predicts malignancy. $\mathrm{Br}$ J Surg 1990; 77: 1023-1024

[3] Nabi Z, Reddy DN. Endoscopic management of combined biliary and duodenal obstruction. Clin Endosc 2019; 52: 40-46

[4] Kawakami H, Kuwatani M, Kawahata S. Peroral ultra-slim endoscopy-guided biliary drainage and stone extraction for postoperative upper gastrointestinal stenosis with a naïve papilla (with videos). J Hepatobiliary Pancreat Sci 2015; 22: 571-572

Bibliography

DOI https://doi.org/10.1055/a-1015-6547

Published online: 11.10.2019

Endoscopy 2020; 52: E110-E111

(c) Georg Thieme Verlag KG

Stuttgart · New York

ISSN 0013-726X

\section{CORRECTION}

ERCP using a conventional upper gastrointestinal endoscope for a patient with a type I duodenal stricture

Maruyama H, Kakiya-Ishikawa Y, Tanoue $\mathrm{K}$ et al. ERCP using a conventional upper gastrointestinal endoscope for a patient with a type I duodenal stricture.

Endoscopy 52, 2020: E110-E111 In the above-mentioned article the name of Hirotsugu Maruyama has been corrected. This was corrected in the online version on March 5, 2020. 